\title{
КАЛОЕВ Б.А. И ЕГО ИССЛЕДОВАНИЯ ТРАДИЦИОННОЙ КУЛЬТУРЫ ОСЕТИН
}

\author{
Т.Е. Дзеранов
}

В статье предпринимается попьтка комплексной оценки научного творчества Б.А. Калоева - одного из ведущих этнографов-кавказоведов ХХ в. Научное наследие Калоева разнообразно по тематике, формам и отраслям. В его трудах исследуются проблемь истории, антропологии и этнографии, историографии и лингвистики, фольклора, религии и мифологии, методологии этнографических исследований. Главным объектом его исследований являлась традиционная культура осетин, и тех народов, чья история и культура были связаны с осетинской. К началу научной деятельности Калоева отечественная наука накопила богатый материал об Осетии и осетинах. Калоев систематизировал, проанализировал и дал свою научную интерпретацию полученному его предшественниками материалу. Особое внимание в статье уделено именно этому аспекту научной деятельности Калоева, посвятившего отдельные исследования своим предшественникам, как дань уважения к их трудам. Отмечая большой личный вклад Калоева в науку, создание им собственной источниковой базы в ходе своих многочисленных экспедииий, автор статьи отмечает, что ученый комплексно изучал культуру и быт единого осетинского этноса и его отдельных территориальных групп (субэтносов), без которых нельзя было создать иелостной картины национальной культурь. Главным объектом исследований Калоева была традиционная духовная и материальная культура осетин. Особое внимание ученый уделил различным формам религии от простейших архаичных до монотеистических, $u$ предложил научную реконструкиию древней религиозной системы осетин, показав проиесс ее развития от скифских времен до Нового времени.

Ключевые слова: традиционная культура, осетины, аланы, мифология, религия, мировоззрение.

The article attempts to give comprehensive assessment of scientific creativity of B. Kaloev, one of the leading researchers of the XXth century ethnography. Scientific heritage of Kaloev encorporates diverse themes, forms and branches. In his works he explores the problems of history, anthropology and ethnography, historiography and Linguistics, folklore, religion and mythology, ethnographic research methodology. The main focus of his research was the traditional culture of the Ossetians, and those peoples whose history and culture have been linked to the Ossetian. By the beginning of the scientific activities of Kaloev our science has accumulated a wealth of material about Ossetia and Ossetians. Kaloyev systematised, analysed and gave his own scientific interpretation to the data obtained by his predecessors. Particular attention in the article is paid namely to this aspect of his scientific activity, devoted to individual studies of each of his predecessors, as a tribute to their work. Noting the great personal contribution of Kaloev into the science and creation of his own material database during his numerous expeditions, the author notes that the scientist comprehensively studied the culture and everyday life of the Ossetian ethnic group in general and separate affinity groups (subethnics), without which it was impossible to create a complete picture of national culture. The main subject of his studies was the traditional spiritual and material culture of the Ossetians. The scholar paid special attention to the various forms of religion from the simplest archaic to monotheistic, and proposed the scientific reconstruction of ancient religious system of the Ossetians, tracing its development from Scythian times till modern times.

Keywords: traditional culture, Ossetians, Alans, mythology, religion, outlook. 
Круг научных интересов Бориса Александровича Калоева был весьма обширен. Научное наследие Б.А. Калоева разнообразно по тематике, формам и отраслям. Он изучал быт, хозяйство и культуру горцев Северного Кавказа: в его трудах исследуются проблемы истории, антропологии и этнографии, историографии и лингвистики, фольклора, религии и мифологии, методологии этнографических исследований.

Но все его разнообразные по форме, методам и проблематике исследования были направлены на один объект, который ученый изучал на протяжении все своей жизни. Этим объектом являлась духовная и материальная культура осетин, и тех древних и современных народов, чья история и культура были связаны с осетинской (скифы, кобанцы, сарматы, горцы и казаки Северного Кавказа, венгерские ясы) $[1 ; 2 ; 3 ; 4 ; 5]$.

Калоев стремился изучить традиционную культуру осетин в полном объеме и разнообразии. Этно- и культурогенез, национальная специфика и единство с культурой древних и современных народов Кавказа и России - вот те проблемы, которыми занимался Борис Александрович Калоев, и внес выдающийся вклад в их решение.

К началу научной деятельности Калоева отечественная наука достигла значительных успехов в изучении истории, языка и культуры осетин и их предков, чья самобытная культура во все времена привлекала внимание современников. «Открытие» осетинского этноса для науки началось с момента присоединения Осетии к России. В 40-е гг. XVIII в., еще до включения Кавказа в состав Российской империи, в Осетию была направлена Осетинская духовная комиссия, миссионерская организация, которая начала свою деятельность с изучения религиозной ситуации и «восстановления православного христианства» в Осетии. В Новое время, с началом процесса присоединения, началось организованное Российской Академией наук планомерное изучение Осетии и ее народа. Среди исследователей Осетии были выдающиеся отечественные и иностранные ученые и путешественники. B XVIII-XIX вв. идет накопление фактического материала об обычаях, обрядах и религиозных представлениях осетин. Содержащиеся в них сведения и сегодня представляют для науки значительный интерес. К началу XX в. русская наука накопила значительное количество материала об Осетии и осетинах.

Этот материал позволил по-новому взглянуть на этногенез, историю, язык, культуру и религию народов Евразии. В одной из своих работ Борис Александрович констатировал: «В центре внимания автора - этногенез и этническая история осетинского народа, вопрос о происхождении которого интересует ученый мир с XVIII в. - со времени появления в Осетии первых европейских ученых и путешественников. С тех давних пор и до наших дней интерес к осетинскому этносу не ослабевает. Огромный вклад в решение этногенеза осетин внесли выдающиеся ученые-языковеды А.М. Шёгрен, В.Ф. Миллер, В.И. Абаев, а также ученые смежных наук» $[6,3]$

Калоев Б.А. отдал дань уважения своим предшественникам, посвятив им отдельные исследования, в которых анализирует их работы и дает оценку вклада каждого из них в отечественную науку. Говоря о Шегрене, Калоев утверждает: «...Шёгрен известен, как основоположник осетиноведения. Составленные им осетинскую научную грамматику (объемом 560 с.) и осетинский практический алфавит на русской графической основе, которым почти без изменения пользовались и последующие исследователи осетинского языка, можно считать научным 
подвигом ученого. В.И. Абаев считает Шегрена первопроходцем осетиноведения, а составленный им алфавит - настолько безукоризненным, что, по словам ученого, ни Вс. Миллер, ни сам Абаев не внесли в него ничего существенного. ...Шёгрен, приехав на Кавказ, следуя примеру Клапрота, впервые доказавшего происхождение осетин от алан, в целях подкрепления этой точки зрения главным объектом своего изучения выбрал осетинский язык и этнографию осетин, тем более что это отвечало его научным интересам. ... В целом... труд Шегрена неоценим для развития осетинской культуры и просвещения». [6, 340]

Также почтительно и бережно относился Борис Александрович к научному наследию Всеволода Федоровича Миллера, которому посвятил статью «В.Ф. Миллер как этнограф осетинского народа» $[6,351-363]$ и монографию «В.Ф. Миллер-кавказовед» [7].

Все исследователи до Бориса Александровича Калоева были специалистами одного-двух научных направлений и проводили исследования, опираясь на методологию своей науки; кроме того, исследования проводились выборочно среди двух основных этнических групп осетинского народа - иронской и дигорской. Такие исследования позволяли объективно оценить уровень развития осетинской культуры, утверждать о ее единстве и специфике; но не позволяли дать полную картину и показать все богатство традиционной культуры осетин.

Калоев на протяжении всей жизни исследовал сохранявшиеся в осетиноведении «белые пятна», последовательно изучал культуру и быт единого осетинского этноса и его отдельных территориальных групп (субъэтносов), без которых нельзя было создать целостной картины осетинской культуры. Объектом его первого научного исследования была субэтническая группа моздокских осетин [8], темой последней, законченной за месяц до смерти монографии были «осетины Восточной Осетии и районов Грузии» [9]. Между этими работами были исследования других осетинских субэтносов, включая этнически связанных с ними венгерских ясов. На материале всех доступных для исследования этнических групп осетин, используя методологию истории, этнографии, лингвистики, искусствоведения и других смежных наук, Калоев смог комплексно изучить традиционную духовную культуру Осетии.

Огромной заслугой Бориса Александровича перед отечественной наукой была его работа по сбору и публикации источников по истории и культуре осетинского народа. Накопленный документальный материал по истории и культуре осетин Калоев Б.А. систематизировал, проанализировал и дал свою научную интерпретацию. Итогом этой работы стала публикация сборников материалов: «Осетины глазами русских и иностранных путешественников» [10] и «Осетины» [11].

Первый сборник включает в себя свидетельства посетивших Северный Кавказ путешественников XIII-XVII вв., в том числе католических миссионеров (Юлиан, Вильгельм де Рубрук, Арканджело Ламберти, Иоанн Мариньола). В него включены также мемуары находившихся на русской службе военных (Л. Штедер, И. Бларамберг) и гражданских чиновников (Я. Рейнеггс, К.Г. Кох) XVIII-XIX веков. Центральное место в сборнике занимают материалы первых научных экспедиций, организованных в тот период Российской Академией наук под руководством русских и западноевропейских ученых (И. Потоцкий, И.А. Гюльденштедт, П.С. Паллас, .-Ю. Клапрот). Большинство из этих материалов либо впервые публиковались на русском языке, либо давно стали раритетами, недоступными для исследователей. Благодаря 
Борису Александровичу они вводились в научный оборот и позволили ему и другим ученым-кавказоведам воссоздать картину состояния осетинской культуры на разных этапах ее развития.

Второй сборник, составленный Б. Калоевым совместно с 3.Б. Цаллаговой, тематически богат и разнообразен. В него вошли материалы, рассказывающие о пути развития культуры осетин с древнейших времен до наших дней. Полно и подробно представлены наиболее яркие образцы народного устно-поэтического творчества (песни, легенды, эпос «Нарты», вошедший в мировое культурное наследие человечества). В книге рассказывается о песенно-музыкальном творчестве осетин, обычаях и традициях, живописи, архитектуре, науке. Дается галерея осетин - видных деятелей отечественной культуры, науки, спорта и политики.

Опираясь на накопленный предшественниками материал по истории и культуре осетин и других горцев Кавказа, Калоев внес большой личный вклад в науку, собирая новые материалы по истории и культуре народа в ходе своих многочисленных экспедиций.

С 1948 г. он был активным участником Дагестанской историко-этнографической экспедиции ИЭ АН СССР, ставшей по существу первым масштабным исследованием советских этнографов народов многоязычного Дагестана. Калоев работал среди лезгин, посвятив им содержательные этнографические очерки, запечатлевшие срез бытовой культуры на период середины прошлого столетия. Позднее в составе Адыгейской этнографической экспедиции ИЭ АН СССР (1950-1960-е годы) Калоев вел интенсивную полевую работу на Северо-Западном Кавказе - в кавказоведении это стало еще одним важным опытом изучения современного состояния кавказских этносов. В архиве Калоева сохранился большой массив этнографических наблюдений, сделанных во время экспедиций в Чечне и Ингушетии. Изучая горцев Северного Кавказа, ученый выявлял общие черты и специфику культуры кавказских этносов.

Но в центре внимания Бориса Александровича всегда была Осетия. Он организовал и провел этнографические экспедиции в различные районы Осетии, а также в места компактного проживания осетин за ее пределами - в Ставропольский край, Грузию и также на территорию потомков алан-ясов - в Венгрию.

Собранный во время экспедиций материал вводил в научный оборот, публикуя монографии и статьи, вошедшие в золотой фонд отечественной науки: «Этнографические данные о связях этногенеза осетин со Средней Азией» [1], «Народы Кавказа. Антропология, лингвистика, хозяйство» (в соавт. с М.Г. Абдушелишвили и С.А. Арутюновым) [3], «Моздокские осетины. Историко-этнографическое исследование» [12], «Венгерские аланы (Ясы). Историко-этнографические очерки» [4], «Осетины Восточной Осетии и районов Грузии. Историко-этнографические очерки» [9].

Обобщающей работой, в которую вошли накопленные ученым материалы, стала его трижды переизданная монография «Осетины» (1-е изд.: М., 1967; 2-е изд.: М., 1971; 3-е изд.: М., 2004). Актуальные статьи по этногенезу, этнокультурным связям осетин с другими народами, и по осетинской мифологии включены Б.А. Калоевым в монографическое исследование «Осетинские историко-этнографические этюды» [6]. Небольшие по объему, но емкие по содержанию статьи были опубликованы в энциклопедических изданиях РАН: «Народы Кавказа» [15, 297-344], «Народы и религии мира» [16, 401-404], «Мифы народов мира» [17], «Осетины» [18, 117-135].

Необходимо отметить, что практически во всех работах по культуре Осетии до Калоева исследователи ограничива- 
лись изучением специфики традиционной духовной культуры осетин. В отличие от своих предшественников Борис Александрович уделял также большое внимание материальной культуре и традиционным видам хозяйства горцев. Приступая к их исследованию, ученый подготовил и опубликовал методическое пособие «Программа сбора материалов по земледелию и скотоводству для «Кавказского историко-этнографического атласа» [13]. Это методическое пособие стало научной программой проводимых Калоевым и его коллегами исследований материальной культуры горцев Северного Кавказа. В 1973 году он издает уникальную для своего времени книгу-альбом «Материальная культура и прикладное искусство осетин» [14]. В этой и других его работах собран богатый материал о быте, одежде, жилищах, музыкальных инструментах, орудиях труда и других артефактах материальной культуры, отражающих богатство этнической культуры горцев.

В течение последующих лет он издает две ставшие классическими монографии по традиционным видам хозяйства горцев - «Земледелие народов Северного Кавказа» [19] и «Скотоводство народов Северного Кавказа с древнейших времен до начала XX века» [20]. В этих работах Б.А. Калоев посвящает целые главы верованиям и обрядам, связанным с сельскохозяйственным календарем горцев. В них он приходит к выводу, что по многочисленным письменным и археологическим источникам, культы, верования и обряды, связанные со скотоводческим хозяйством горцев, можно считать более древними, чем подобные им земледельческие. Некоторые из них восходят к периоду зарождения пастушеского скотоводства. Сюда можно отнести почитание святых - покровителей крупного и мелкого рогатого скота, в частности быка и барана, изображения которых на предметах материальной культуры имеются в изоби- лии в памятниках различных археологических эпох Северного Кавказа, прежде всего майкопской и особенно кобанской.

Анализируя традиционные верования и обряды горцев, ученый утверждает: «Данные свидетельствуют... что аграрные культы и обряды, как и в целом дохристианские и домусульманские верования, больше всего сохранились среди жителей горной зоны, быт которых характеризуется вообще глубокой архаикой. Суровые природные условия, особенно центрального горного Кавказа, географическая изолированность горцев в труднодоступных местах способствовали сохранению у них до недавнего времени их народной религии.

Богатым и сложным циклом аграрных культов и обрядов особенно отличались осетины. Сохранение осетинами древних дохристианских верований объясняется не только слабым влиянием христианства и мусульманства, но и особенностями их природной среды и быта в горах» [19, 202-216].

Духовная традиционная культура осетин в творчестве Калоева всегда оставалась главным объектом исследований ученого. Важной частью духовной культуры он считал религию и мифологию, религиоведческие проблемы рассматриваются в большинстве работ ученого. Он смог дать научную реконструкцию древней религиозной системы осетин, показать процесс ее развития от скифских времен до Нового времени. В своих работах ученый рассматривает различные формы религии от простейших архаичных до монотеистических.

В своих исследованиях духовной культуры осетин Калоев часто обращался к материалам своих предшественников А.М. Шёгрена, В.Ф. Миллера и современника В.И. Абаева.

Отмечая вклад Шёгрена в исследование духовной культуры осетинского народа, Борис Александрович обращает 
внимание на то, что «Шёгрен впервые дает нам описание главных полуязыческих-полухристианских божеств осетин Уацилла, Мьккалгабыр, Мадьмайрам, Уастьрджи и т.д. и их функций. О последнем он пишет так: «Святой Георгий победоносец почитается покровителем путешествующих и всех дорог, ему молятся и приносят жертвы, отправляясь на войну, в набег или в дорогу. Здесь мы убеждаемся еще раз, что Уастьрджи (св. Георгий) наделен чертами аланского бога войны. Мы обязаны Шегрену и первыми сведениями о таких древних святых, как фьрь-дзуар (покровитель барана), восходящий к кобанской эпохе, почитавшийся еще в недавнем прошлом восточными осетинами, и хуцзауы-дзуар (святой бога); его святилище находится в селении Лац Куртатинского ущелья, известном и другими аланскими памятниками и памятниками нартского эпоса» $[6,345]$

По мнению Калоева, Шёгрен первый в кавказоведении обратил внимание на наличие «многого сходного» в религии, обрядах и обычаях осетин и ингушей. Многие праздники в честь языческих божеств осетин и вайнахов, не известные до Шёгрена в литературе, рассматриваются им «впервые отдельно и в сравнительном плане». Спустя почти 200 лет Калоев подтверждает эти слова Шёгрена своими многократными наблюдениями во время экспедиционных поездок по Чечне и Ингушетии» $[6,343]$.

Много общего у осетин с народами Кавказа, главным образом Западного, прослеживается и в образе другого эпического божества, Курдалагона, - покровителя кузнецов, известного у адыгов под именем Тлепша, а у абхазов - Динара.

Анализируя в своих работах вклад В.Ф. Миллера в осетиноведение, Калоев отмечал, что ученый уделял большое внимание «изучению религиозных верований осетин. Еще во время первой своей поездки (1880 г.) по горной Осетии он записал много преданий о возникновении отдельных осетинских святилищ (дзуаров), присутствовал на некоторых празднествах, в частности, побывал на пиршестве в честь известного святилища Реком (селение Цей), собирал материал об осетинских похоронных обрядах.

Миллер отмечал, что ему никогда не случалось видеть в Осетии «ни ханжества, ни религиозного фанатизма». Основной религией у осетин, по определению ученого, были языческие верования, созданные самими горцами. «Осетин, - писал Миллер, - называет ли он себя христианином, или мусульманином, - в сущности - язычник. Его религия сводится к тому, что в известные дни следует зарезать барана, или быка, пойти на известное “святое место" пропеть в честь местного дзуара восхваление, - затем его долги небу оплачены» $[21,362]$.

Калоев анализирует реконструируемую Миллером религиозную систему осетин. «Рассматриваемая работа Миллера состоит из введения и пяти разделов, в которых описываются осетинские божества и дзуары, общественные праздники, домашние обряды и пр. По утверждению Миллера, у осетин, как и у других народов Кавказа, существует представление о едином боге - Хуиау, пребывающем на небе и управляющем миром. Но в повседневной жизни счастье и несчастье людей зависят от вмешательства других сил, заведующих разными областями природных явлений и подчиненных высшему богу. От одного из этих духов зависит урожай хлеба, от другого - обилие и здоровье домашнего скота, третий заведует дикими животными и дает удачу на охоте, четвертый посылает урожай меду И Т.д.».

В историко-этнографическом исследовании «Осетины», Борис Александрович Калоев, используя накопленный предшественниками и собственный, собранный в экспедициях полевой матери- 
ал, систематизировал его и реконструировал древнюю религиозную систему религиозных верований осетин. Он делит осетинские верования по хронологическому принципу на три пласта:

I. Пережитки древнейших форм религии - тотемизм и анимизм.

II. Дохристианские культы.

III. Официальные религии:

а) Христианство в Осетии

б) Мусульманство в Осетии

Дохристианские культы он разделяет по значимости:

1. Общеосетинские дзуары

2. Ущельные культы

3. Сельские культы

4. Родовые культы [5, 235-296].

Рассматривая дохристианские верования осетин, он обращает основное внимание на характеристику древних божеств, игравших важную роль в религиозной жизни этого народа.

Религиозное мировоззрение осетин, как и любого народа, складывалось в течение многих веков. Оно имеет несколько различных пластов, возникших в разные эпохи и в разной этнокультурной среде.

Сохранившиеся у осетин элементы тотемистических и анимистических верований дают интересный материал для их этногенеза.

В религиозных системах предков осетин особую роль играли олень, конь, волк, орел и ворон. Данные тотемы воспринимались соседними народами.

$\mathrm{Ha}$ памятниках позднекобанской культуры из Осетии изображение оленя известно в двух видах - «скифского оленя» и «благородного оленя». По определению В. И. Абаева, одно из больших племен скифов - саки, обитавшее в Средней Азии, носило имя тотемного животного (саг, осет. «олень»).

Другим тотемом у ираноязычных предков осетин был волк (бирагъ), именовавшийся в древности уархаг. Волк был тотемным животным у тюркских наро- дов, находившихся в контакте с предками осетин со скифских времен, и у соседей вайнахов. В осетинском быту волк давно перестал быть тотемным животным, но отголоски былого тотемизма довольно ясно прослеживаются в нартовских сказаниях.

Более разнообразными Калоев считает те религиозные верования, которые сложились на кавказской почве и отличаются весьма близким сходством с подобными религиозными верованиями соседних кавказских народов. Кавказские черты в религии осетин характеризуются многообразием, устойчивостью и глубоким архаизмом.

Из местных кавказских тотемистических представлений у осетин наибольшего внимания заслуживает почитание медведя как тотема. Однако этот тотем был распространен лишь среди южных осетин, отличающихся наличием ряда других архаических черт в религии и быту.

К числу кавказских черт тотемизма относится почитание некоторыми фамилиями в Северной и Центральной Осетии орла и ворона. Как отголосок тотемических родовых культов наиболее широкое распространение в Осетии имеет почитание ворона.

Вместе с тем, несомненно, змея также была одним из древнейших кавказских тотемов. Свидетельством этого могут служить изображения змеи на многих бронзовых предметах из кобанских могильников Осетии, а также частое упоминание ее в нартских сказаниях под названием Залиаг Калм (Залийская Змея), а в более поздних фольклорных текстах - змея Раумула.

Наряду с кавказскими, в верованиях осетин обнаруживается немало и древнеиранских черт, присущих скифо-сарматским и аланским племенам. Сохранение в быту в большом количестве древних религиозных верований объясняется во 
многом слабым развитием здесь официальных религий. Христианство, получившее распространение у алан-осетин еще в средние века, не проникло столь глубоко и прочно, чтобы полностью уничтожить все религиозные культы алан-осетин, но все же наложило сильный отпечаток на их дохристианские верования.

Внимание Б.А. Калоева привлек уходящий корнями к скифо-сарматскому периоду алано-осетинский культ в честь семи богов - Авддзуары (семибожие), пользовавшийся, несомненно, в старину большой популярностью и совершенно неизвестный соседним народам. Геродот приводит название семи богов (Тобити, Папай, Апи, Оптосир, Артимпаса, Геракл, Арей), почитавшихся скифами. Культ в честь семибожия у осетин характеризуется наличием фамильных и сельских святилищ, еще сохранившихся в ряде мест Осетии.

Таким образом, приведенный Б.А. Калоевым материал свидетельствует о сохранении у осетин одного из древнейших культов скифов, сарматов и алан. Происхождение культа семи божеств получило глубокий анализ в работе В.И. Абаева на основании лингвистических данных. Этнографический материал вполне подтверждает основной его вывод: «...Культ семи богов с удивительным постоянством прослеживается на протяжении огромного периода - от геродотских скифов через алан до современных осетин».

Анализируя религиозную ситуацию в Осетии, Калоев отмечал: «Осетины относятся к числу тех немногочисленных народов Кавказа, которые имели две официальные религии - христианство и ислам... Однако ни христианство, ни ислам не утвердились в народе, тем не менее, эти религии, главным образом христианство, оказали немалое влияние на мировоззрение осетин». [5, 283]

Древняя традиционная религия не исчезла после принятия христианства в Алании. «Дохристианские религиозные верования после монгольского нашествия и оттеснения осетин в горы получили еще более широкое распространение. Этот период характеризуется появлением в горах Осетии множества родовых, общинных и ущельных культов, а также окончательным сложением общеосетинского пантеона.

Укрепление дохристианских верований осетин в горах после монгольского нашествия и упадка христианства объясняется не только экономическими и социальными факторами, но и во многом - географическими условиями жизни народа, что не раз отмечалось еще дореволюционными авторами» $[5,235-236]$. «...Замкнутые условия жизни горных осетин в течение нескольких веков (XIVXIX вв.) способствовали укреплению древних верований в быту этого народа, так что новая волна христианизации (после вхождения Осетии в состав России. Т.Д.), а позднее внедрение мусульманства не смогли искоренить эти верования до конца» $[5,287]$.

Калоев также отмечал, что «в горах более прочно держится и старая осетинская семейная обрядность, характеризующаяся наличием многих древних религиозных воззрений, особенно в погребальных и поминальных обычаях... Отметим также, что в семье осетин независимо от места ее жительства - в горах или на равнине - религиозные воззрения и предрассудки находят свое распространение преимущественно среди людей пожилого возраста» $[5,295]$. «В горах же еще до недавнего времени по традиции продолжалось почитание ряда популярных общеосетинских, общинных и даже фамильных культов; устраивались жертвоприношения, общественные пиршества и т.д. Однако для большинства населения эти празднества уже утратили религиозную сущность... Многие из таких празднеств, особенно 
в честь аграрных культов, хотя и имели религиозную окраску, внешне почти ничем не отличались по своему характеру от современных колхозных праздников» $[5,294]$.
Значительное место в исследованиях Калоева занимает светская культура осетин: прикладное искусство, песенно-музыкальное творчество, живопись, архитектура, наука.

1. Калоев Б.А. Этнографические данные о связях этногенеза осетин со Средней Азией // Вопросы иранской и общей филологии. Тбилиси, 1977.

2. Калоев Б.А. Некоторые этнографические параллели к осетинскому нартскому эпосу // Сказания о нартах - эпос народов Кавказа. М., 1969.

3. Калоев Б.А. Народы Кавказа. Антропология, лингвистика, хозяйство. М., 1994 (в соавт. с М.Г. Абдушелишвили и С.А. Арутюновым).

4. Калоев Б.А. Венгерские аланы (Ясы). Историко-этнографические очерки. М., 1996

5. Калоев Б.А. Осетины. Историко-этнографические исследования, 2-е изд. М., 1971

6. Калоев Б.А. Осетинские историко-этнографические этюды. М., 1999.

7. Калоев Б.А. В.Ф. Миллер - кавказовед. Исследование и материалы. Орджоникидзе, 1963.

8. Калоев Б.А. Землевладение и землепользование у моздокских осетин // Советская этнография. 1952. № 1. С. 179-183.

9. Калоев Б.А. Осетины Восточной Осетии и районов Грузии. Историко-этнографические очерки. Владикавказ, 2012.

10. Осетины глазами русских и иностранных путешественников (XIII-XIX вв.). Орджоникидзе, 1967.

11. Осетины. М., 2007.

12. Калоев Б.А. Моздокские осетины. М., 1995.

13. Калоев Б.А. Программа сбора материалов по земледелию и скотоводству для «Кавказского историко-этнографического атласа». М., 1968.

14. Калоев Б.А. Материальная культура и прикладное искусство осетин. Книга-альбом. М., 1973.

15. Народы Кавказа. М., 1960. Т. 1.

16. Народы и религии мира М., 2000.

17. Мифы народов мира. Энциклопедия: в 2-х т. М., 1991-1992. Т. 1-2.

18. Осетины. М., 2012.

19. Калоев Б.А. Земледелие народов Северного Кавказа. М., 1981.

20. Калоев Б.А. Скотоводство народов Северного Кавказа с древнейших времен. M., 1993.

21. Миллер В.Ф. В горах Осетии. Владикавказ, 1998. 